\title{
Delivering the Goods: Legislative Particularism in Different Electoral and Institutional Settings
}

\author{
Scott Ashworth Princeton University \\ Ethan Bueno de Mesquita Washington University
}

\begin{abstract}
We analyze a model of legislative particularism to understand how the provision of constituency service responds to variations in institutional and electoral environments. We show that increased partisan balance in the electorate, single-member districts, and independent executives all increase incentives for legislators to provide constituency service. The results of the model are consistent with existing comparative-institutional empirical observations. Moreover, the model addresses over time trends in the United States that are not explained by existing models and yields novel hypotheses that are amenable to empirical evaluation.
\end{abstract}

T here is substantial variation in the amount of constituency service legislators provide across different political environments. Comparisons of the U.S. Congress and the U.K. Parliament show that representatives in single-member district, presidential systems do more constituency service than those in single-member district, parliamentary systems (Cain, Ferejohn, and Fiorina 1987). Studies of U.S. state legislatures (Jewell 1982; Welch and Studlar 1990) and of comparative national legislatures (Heitshusen, Young, and Woods 2005) show that representatives do less work specifically geared toward their constituents in multimember districts than in singlemember districts. However, contrary to these findings, some types of multimember district systems (such as that which existed in Japan) appear to lead to high levels of legislative particularism (Hirano 2002). Finally, constituency service by members of Congress has increased over the last 40 years (Shepsle 1989).

We present a model of constituency service provision and explore its predictions in different stylized institutional and electoral settings. The model's most novel contribution is that it allows us to examine how the level of constituency service changes with shifts in the partisan balance of the electorate. We also analyze changes in constituency service under two types of institutional variation: single-member versus multimember districts and presidential versus parliamentary systems. While the model clearly omits important determinants of constituency service (e.g., parties), the comparative statics are broadly consistent with a variety of empirical trends and the model yields several testable hypotheses.

In our model, legislators invest resources in constituency service to enhance their reelection probabilities. The amount of constituency service provided is determined by two factors: a legislator's ability and the resources she invests. Voters consider two things when voting: the policy preferences of their legislator and her ability to provide both constituency service and global public goods. ${ }^{1}$ All else equal, voters prefer highability representatives, but they receive only a noisy signal of ability by observing the constituency service provided to the district. Politicians expend scarce resources in order to convince the voters, through high levels of constituency service, that they are of high ability. Voters, in choosing a candidate, have to balance their policy preferences and their assessments of the candidates' abilities. The comparative statics investigate how different institutional and electoral

\footnotetext{
${ }^{1}$ Global public goods provision, in our conceptualization, includes those activities that require legislative effort and which benefit the country as a whole. Such activities might include bureaucratic oversight, vetting presidential nominees, or improving the quality of legislation (holding fixed its ideological content).
}

The Journal of Politics, Vol. 68, No. 1, February 2006, pp. 168-179 
arrangements affect the voters' decisions and, consequently, politicians' incentives for providing constituency service.

We first compare a change in the electoral environment, in particular, a shift toward greater partisan balance. When electorates are more balanced, the decisive voter in each district is more likely to be swayed by incumbent ability. Consequently, the marginal expected benefit that legislators derive from constituency service increases. This leads to the prediction that there is more constituency service when districts are more balanced between the parties. We use this result to discuss over time trends in the Congress.

We then compare a stylized single-member district, presidential system to a stylized single-member district, parliamentary system. In the parliamentary system, the legislature determines national policy on its own, unconstrained by an independent executive (which exists in the presidential system). As a result, parliamentary voters care more than do presidential voters about the policy views of their representatives and less about their representatives' abilities to provide constituency service. Consequently, parliamentary representatives have less incentive to do constituency service. Moreover, incentives for constituency service provision within presidential systems decrease as the president becomes more powerful.

The final comparison we consider is between stylized single-member and multimember district systems. Single-member districts allow for more learning about ability than do multimember districts, since voters in multimember districts do not know which of their representatives to credit for benefits provided to the district. Consequently, voters place more weight on individual characteristics in singlemember districts, giving the legislators greater incentive to engage in constituency oriented activities. We use these results to analyze why voters might elect divided delegations in multimember district systems.

\section{The Literature}

Several institutional theories link comparative patterns in constituency service with patterns in party strength, based on the idea that strong parties, concerned with preserving the party's reputation for providing national public goods, may limit the resources party members can devote to legislative particularism We refer to such theories as party-based models (Carey and Shugart 1995; Cox and McCubbins 1993). These authors suggest that institutions which support strong parties, such as parliamentary forms of government, will also lead to relatively low levels of legislative particularism. Cain, Ferejohn, and Fiorina (1987) find empirical evidence that supports this theory: members of the United States Congress (with its relatively weak parties) do more constituency service than do members of the British Parliament (with its relatively strong, disciplined parties).

The last several decades have seen an increase in party cohesion in Congressional voting (Aldrich 1995; Rohde 1991) and party organizations have become more assertive in policymaking (Rohde 1991; Shepsle 1989). In light of the party-based models, it is surprising, then, that House members actually do more constituency service today than they did 40 years ago (Shepsle 1989). This increased focus on local concerns can be seen in Figure 1, which shows the percent of congressional staff based in district offices by year. ${ }^{2}$

The over-time relationship between party strength and constituency service is precisely the opposite of the cross-national relationship that gave rise to the party-based models. This empirical fact creates theoretical space for approaches, such as ours, which look at causes of constituency service that do not depend on parties. Thus, we propose a model without parties and demonstrate that, while clearly a simplification, it seems to be consistent with the historical trend in the United States that the party-based models cannot address. Furthermore, the mechanism we identify allows us to make an additional institutional comparison not covered by the party-based theories-single-member versus multimember districts.

In addition, we show that the model is consistent with the comparative facts that inspired the partybased theory. While we do not offer our model as a replacement for that theory, if our proposed causal mechanism had comparative predictions strongly at variance with the established comparative facts or theories, then we would have less confidence in it. The fact that when they overlap our model's and the partybased models' predictions are in the same direction means that the two models can be viewed as complementary components of a (yet to be constructed) larger model of comparative legislative particularism.

\section{The Model}

There are two periods. At the beginning of the game, each of $n$ districts has an incumbent representative in a unicameral legislature, who is equally likely to be

${ }^{2}$ See Fiorina and Rivers (1989) for a discussion of this statistic as a measure of constituency service. 


\section{Figure 1 Percent of U.S. House Staff in District Offices}

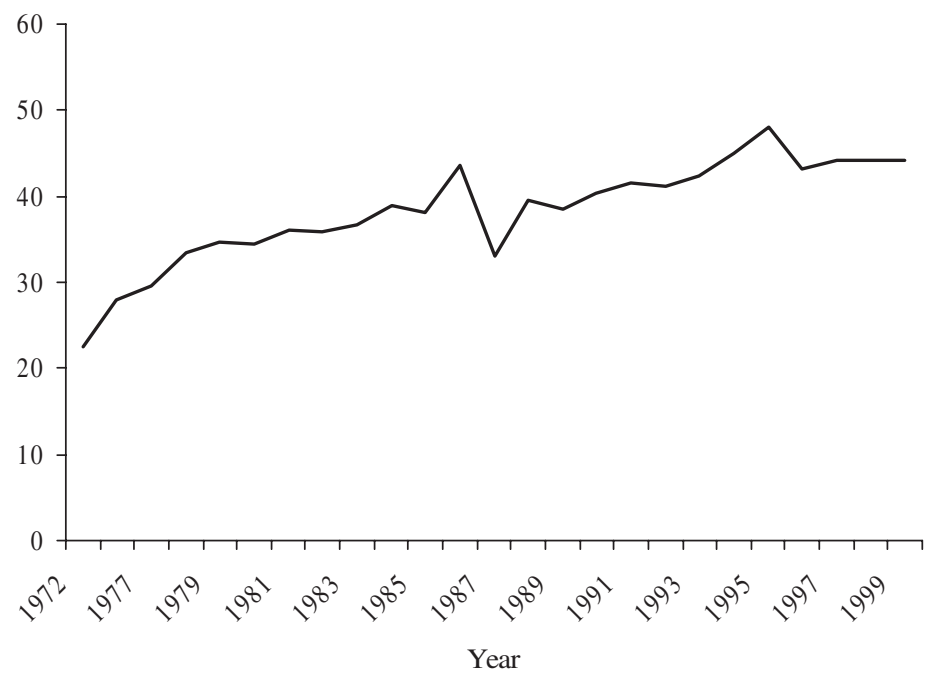

Source: Data from Ornstein, Mann, and Malbin (2002).

from either of the two parties. ${ }^{3}$ In period 1, incumbent legislators divide their resources between local and global public goods provision, and the legislature sets national policy. Each voter observes the total amount of constituency service provided to his district. In period 2, legislators stand for reelection and those elected once again divide resources between constituency service and global public goods and set national policy.

\section{Partisan Preferences}

There are a left $(L)$ and a right $(R)$ party, with fixed policy platforms in the one-dimensional policy space $(-\infty, \infty)$. We denote these platforms by $\mu_{j}$, where $j \in$ $\{L, R\}$, and assume $\mu_{L}=-\mu_{R}$. Candidates are assumed to have the same policy positions as their parties. ${ }^{4,5}$

The representative voter in a district has policy preferences represented by the expectation of $-\left(x^{\star}-\right.$

${ }^{3}$ We could have a first-round election. However, since all politicians are ex ante identical and no information has been revealed prior to period 1 , this election would simply involve voters choosing randomly.

${ }^{4}$ We could relax this symmetry assumption by assuming that party caucuses are distributions around this mean and voters are informed of party labels but not candidate-specific divergence from party platforms. While this assumption would look slightly more realistic, it would increase notational complexity without adding any insight.

${ }^{5}$ In our companion paper focusing on party discipline (Ashworth and Bueno de Mesquita 2004), candidates are not perfect agents of parties, so the voter believes that a party p's candidate's policy preference is a random variable. To make the link between the papers, interpret $\mu_{p}$ as the voter's certainty equivalent of this random variable. $x)^{2}$, where $x$ is a policy and $x^{\star}$ is the voter's ideal point. The candidates do not know $x^{\star}$; their common belief is that $x^{\star}$ is distributed normally with mean 0 and variance $\sigma_{x^{*}}^{2}$ for each district, and that these ideal points are mutually independent. ${ }^{6}$

\section{What Legislators Do}

Legislators, in our model, influence governmental outputs in three ways: providing local goods for their constituents, providing global public goods that benefit the whole country, and voting on legislation. The provision of local goods might include activities such as constituency service or securing pork-barrel projects for the district. For most of the paper we will focus on constituency service and will refer to the provision of local goods in this way. However, we will return to the idea of pork production later in the paper. There are also several activities that might constitute global public goods provision. These include oversight of the bureaucracy, vetting of presidential nominees, and improving the quality of legislation (holding fixed its ideological content). Since the provision of both local and global goods might include voting on bills, we conceptualize the third activity in which legislators in our model engage- - voting on legislation-as voting specifically on those policy issues which do not involve any public goods component. Here we have in mind such ideological issues as abortion rights, the legality of stem cell research, or the permissibility of gay marriage.

${ }^{6}$ Later, we relax the assumption that districts are ex ante identical. 
Each legislator has resources $D$ which she divides between constituency service (local goods) and global public goods provision. We conceptualize these resources as including staff, office budget, and time. ${ }^{7}$

Two factors determine the amount of constituency service that a legislator provides: the amount of resources the legislator devotes to constituency service $(a)$ and her ability $(\theta \in \mathbb{R})$. We assume that ability is unobserved ex ante, and the common belief is that it is drawn from a normal distribution with mean $m>0$ and variance $\sigma_{\theta}^{2}$. The total amount of constituency service provided by a legislator, $i$, who invests resources $a_{i}$ and has ability $\theta_{i}$ is $g_{i}=a_{i} \theta_{i}+\varepsilon_{i}$, where $\varepsilon$ is normally distributed with mean 0 and variance $\sigma_{\varepsilon}^{28}$.

Resources not devoted to constituency service are directed toward providing global public goods which affect the whole country. The legislator's success at providing these global public goods is a function of the resources devoted to global public goods $\left(p_{i}=D_{i}\right.$ $-a_{i}$ ) and ability $\left(\theta_{i}\right)$. The total amount of global public goods provided by a legislator $i$ is $G_{i}=\theta_{i} u\left(p_{i}\right)$, where $u(\cdot)$ is increasing, strictly concave, and satisfies $u^{\prime}(0)>$ 1 and $u^{\prime}(D)<1 .^{9}$ These assumptions insure that all legislators are willing to invest resources in both types of activities, though the precise amounts will depend on parameter values.

Finally, as a reduced form, we assume that the bundle of national policies set by the legislature is an average of legislator ideal points in a one-dimensional policy space. One might think that policy outcomes should reflect the median, rather than the mean. As reduced form representations of multidimensional legislative bargaining, both the mean and median capture the intuition that policies tend to be centrist. Moreover, the substantive implication of assuming that policy outcomes reflect the median legislator's preferences is that no legislator's policy preferences, other than the median's, have any impact on outcomes. However, empirically, it seems clear that nonmedian legislators exert influence on policy. Thus, the mean satisfies two intuitively appealing criteria: (1) it is centrist and (2) it is responsive to the preferences of more than one legislator. The median is centrist but

${ }^{7}$ Later we consider the possibility that majority and minority party members have different levels of resources.

${ }^{8}$ This model of constituency service is based on the model of career concerns in Holmström (1999) and Dewatripont, Jewitt, and Tirole (1999). Such models have previously been applied to elections by Alesina and Tabellini (2003), Ashworth (2005), Lohmann (1998), and Persson and Tabellini (2000).

${ }^{9}$ For a discussion of other production functions in public goods games, see Sandler (2004). not responsive. Responsiveness is important in the model because it has the implication that voters in all districts care about the policy preferences of their representatives.

It is also worth noting that we are abstracting away from the full complexity of legislative bargaining in another way. In reality, all of the legislative outputs we study (local goods, global public goods, and policy) are the result of the strategic interactions of legislators. We restrict attention to the resource allocation decisions of individual legislators because our focus is on individual incentives to provide local goods.

\section{The Election}

In period 2, the voter chooses to return the incumbent or elect a challenger who is randomly selected from the opposition party. The voter observes the level of constituency service provided to his district before the election but does not observe the global public goods until after the election. The justification for this timing assumption is that constituency service is an immediate benefit to the voters, and thus observed in the short-run. The provision of global public goods, however, involves both "inside the beltway"-type oversight functions, which are difficult for voters to observe, as well as policy work on long-term issues, such as infrastructure, defense, and basic research, the benefits of which may not be observed by the voters for a long time.

\section{Payoffs}

The voters have preferences over policy, constituency service, and global public goods. In particular, the voter in district $i$ has per-period expected utility given by

$$
\mathbb{E}\left[-\left(x_{i}^{*}-x\right)^{2}+g_{i}+\alpha \sum_{i=1}^{n} G_{i}\right]
$$

where $\alpha$ represents the relative weight the voter puts on constituency service versus other legislative outputs. A candidate in district $i$ has preferences over reelection, policy, constituency service, and global public goods given by

$$
\mathbb{E}\left[\operatorname{Pr}\left(\text { reelect } \mid a_{i}, \theta_{i}\right) B+g_{i}+\sum_{i=1}^{n} G_{i}\right]
$$

where $B$ is the net benefit to reelection. ${ }^{10}$ Notice that we allow the voter and the candidate to put different weights on the global public goods.

\footnotetext{
${ }^{10}$ This benefit includes both the "ego rent" from holding office and
} the private portion of the payoff to public goods, $(1-\alpha) G_{i}$. 


\section{Equilibrium}

Our main goal is to examine how investment in constituency service changes in different institutional and electoral environments. To do this, we must describe the equilibrium of the game, which we do in this section. We first discuss how the voter chooses whether to reelect the incumbent. We then determine how legislators allocate their resources between constituency service and global public goods given these electoral incentives.

Since the model is symmetric, the decision problem is the same for left- and right-wing incumbents. For concreteness, we focus on a left-wing incumbent. Let $m_{L}$ and $m_{R}$ represent the voter's posterior beliefs about the ability of the left- and rightwing candidates respectively. (Note that since we are focusing on a left-wing incumbent, $m_{R}=m$.) The voter chooses which candidate to elect by comparing the expected utility of each choice.

Lemma 1 The voter votes for the left-wing candidate if and only if $m_{L} \geq 2\left(\mu_{R}-\mu_{L}\right) x^{*}+m_{R}$.

The proof of this, and all future results, is in the online appendix at http://www.journalofpolitics.org.

The voter's voting rule takes two factors into consideration: the voter's posterior beliefs about the candidates' abilities $\left(m_{L}\right.$ and $\left.m_{R}\right)$ and the voter's policy preferences. The term $2\left(\mu_{R}-\mu_{L}\right) x^{\star}$ represents the policy component of the voter's choice. When this term is positive $\left(x^{\star}>0\right)$, the voter prefers a right-wing candidate, other things equal. Similarly, when this term is negative $\left(x^{*}<0\right)$, the voter prefers a left-wing candidate, other things equal. Intuitively, if the voter were indifferent between the two parties on policy grounds $\left(x^{*}=0\right)$, then he would vote for the left-wing candidate if he believed that left-wing candidate's ability $\left(m_{L}\right)$ was higher than the right-wing candidate's ability $\left(m_{R}\right)$. Similarly, if the voter believed the two candidates were of identical ability $\left(m_{L}=m_{R}\right)$ he would vote for the right-wing candidate if he was a right-leaning voter $\left(x^{*}>0\right)$ and vote for the leftleaning candidate if he was a left-leaning voter $\left(x^{\star}<\right.$ $0)$. Since the policy term will play a major role in the analysis, we introduce the following notation: $\eta \equiv 2\left(\mu_{R}\right.$ $\left.-\mu_{L}\right) x^{*}$.

Since the voter's belief about the incumbent's ability is also important, it is worth briefly examining how these beliefs are formed. The voter observes the amount of constituency service provided to the district $\left(g_{i}=\theta_{i} a_{i}+\varepsilon_{i}\right)$. As we said before, the voter has prior beliefs about the incumbent's ability that are dis- tributed normally with mean $m$. Let $a_{i}^{\star}$ represent the voter's expectation about the amount of resources the incumbent will devote to constituency service. Given this, the mean of the voter's posterior belief $\left(m_{L}\right)$ about the incumbent's ability is a weighted average given by:

$$
m_{L}=\lambda \frac{g_{i}}{a_{i}^{\star}}+(1-\lambda) m,
$$

where $\lambda$ depends on parameters and is defined formally in the appendix. The intuition of this updating formula is that the voter gives weight to both his prior beliefs about his incumbent's ability and to the new information he obtains by observing the amount of constituency service provided. Notice, in particular, that the larger the actual amount of constituency service provided $\left(g_{i}\right)$, relative to the amount the voter expected $\left(a_{i}^{*}\right)$, the higher ability the voter believes the incumbent to have, in expectation. It is for this reason that investing in constituency service can increase an incumbent's probability of electoral success.

Remark 1 The greater the amount of constituency service provided, relative to the voter's expectations, the higher the probability that the incumbent is reelected.

In light of the voting rule and updating, the incumbent can figure out how any given division of resources between constituency service and global public goods will affect his reelection chances. In particular, the voter is voting, in part, based on his assessment of incumbent ability $\left(m_{L}\right)$. The only signal of the incumbent's ability that the voter observes before voting is the amount of constituency service. ${ }^{11}$ Thus, were the incumbent to invest more resources in constituency service than the voter expected, the voter would be "fooled" into believing the incumbent was of higher ability than is accurate. The incumbent trades off this consideration against his preferred resource allocation to arrive at this optimal allocation. The process by which the voter learns about incumbent ability, and the incumbent's optimal choice, are formally analyzed in the appendix and summarized in the following result.

Lemma 2 The amount of resources the incumbent devotes to constituency service is $a^{*}$ and to global public goods is $p^{*}=D-a^{*}$, where $a^{*}$ is unique and satisfies the following:

\footnotetext{
${ }^{11}$ This timing assumption is actually a bit stronger than we need. Ashworth (2005) and Lohmann (1998) study similar models showing that the key assumption is that one type of legislative output be observed more accurately than the other.
} 


$$
\frac{B \phi(0)}{a^{\star} \sigma\left(a^{*}, a^{*}\right)}=u^{\prime}\left(D-a^{*}\right)-1,
$$

where $\sigma(a, a)$ is a function defined in the appendix.

The intuition underlying the incumbent's choices is as follows. On the one hand, the marginal benefit of increased spending on constituency service is that it makes it more likely the voter will observe a good signal of incumbent ability (the left-hand side of equation (2)). As shown in Lemma 1, this makes the voter more likely to reelect the incumbent. On the other hand, increasing resources devoted to constituency service comes at the expense of global public goods (the right-hand side of equation (2)).

Recall that the voter and the legislator may disagree about the value of constituency service versus global goods. This is formalized in the $\alpha$ term in the voter's expected utility. In general, it is reasonable to think the voter will value local concerns more than the legislator $(\alpha<1)$. This is because, while the global goods that a legislator invests in provide benefits for the whole country they may also provide private benefits for the legislator by furthering issues of personal importance to her, building political capital with the party, or helping to secure campaign donations. The following result shows that, if voters prioritize local concerns over global goods enough, then, even with electoral incentives, the legislator will underprovide constituency service from the voter's perspective.

Lemma 3 There exists an $\bar{\alpha}>0$ such that, if $\alpha<$ $\bar{\alpha}$, then the legislator provides less constituency service than the voter would like.

The value of $\alpha$ dose not affect our analysis. All of our comparative statics hold whether the legislator provides too much or too little constituency service, from the voter's perspective. However, occasionally it will help with intuition to be able to focus on the case where $\alpha<\bar{\alpha}$.

\section{Institutional and Electoral Variation}

\section{Majority versus Minority Status}

In the U.S. Congress, and many other legislatures, the division of resources is not equal across members. This inequality may be along a variety of dimensions. For example, committee chairs are allotted extra staff. A particularly important form of resource inequality is between members of the minority and majority parties. $^{12}$

Not surprisingly, when given extra resources, legislators increase their total output of both constituency service and global public goods. Thus, while we do not model the internal legislative bargaining that determines the resources made available to each representative, our model is consistent with the intuition that members of the majority party will be able to better provide for their districts.

Proposition 1 The equilibrium levels of both constituency service and global public goods provided by a legislator are increasing in the resources to which that legislator has access.

\section{Changes in Partisan Balance}

What happens to the level of constituency service as the voters in a district become less partisan? Intuitively, as the voters become more balanced between the parties, the pivotal voter is more likely to be indifferent between the two parties on the policy dimension, making it more likely that beliefs about ability will affect the election outcome. As suggested by Remark 1, this increases the incentives incumbents have to invest in constituency service.

In order to explore this formally we generalize our model, allowing districts to lean toward one of the two parties. We assume that a district's pivotal voter's ideal point is distributed normally with mean $\gamma$ and variance $\sigma_{x}^{2}$. The parameter $\gamma$ measures partisan balance. A negative value of $\gamma$ indicates a district that leans left, while a positive value indicates a district that leans right. Thus, a district becomes more balanced as $\gamma$ approaches 0 .

In general, a district of a given partisan leaning can expect a different level of constituency service form left- and right-wing representatives. This is because the partisan leanings of the district affect voting behavior and, therefore, the incentives for constituency service. The relationship is formalized in the following result and illustrated in Figure 2.

Proposition 2 The level of constituency service provided by a left-wing (right-wing) representative is maximized in a moderately right-wing (left-wing) district and is decreasing as the partisanship of the district moves away from this maximum in either direction. ${ }^{13}$

${ }^{12}$ We thank an anonymous referee for suggesting this line of argument.

${ }^{13}$ Without partisan balance, we are not assured of a unique equilibrium. However, as shown in the appendix, this result holds for all stable equilibria. 
FIGURE 2 Right-wing representative's constituency service is maximized in moderately left-wing districts and left-wing representative's constituency service is maximized in moderately right-wing districts

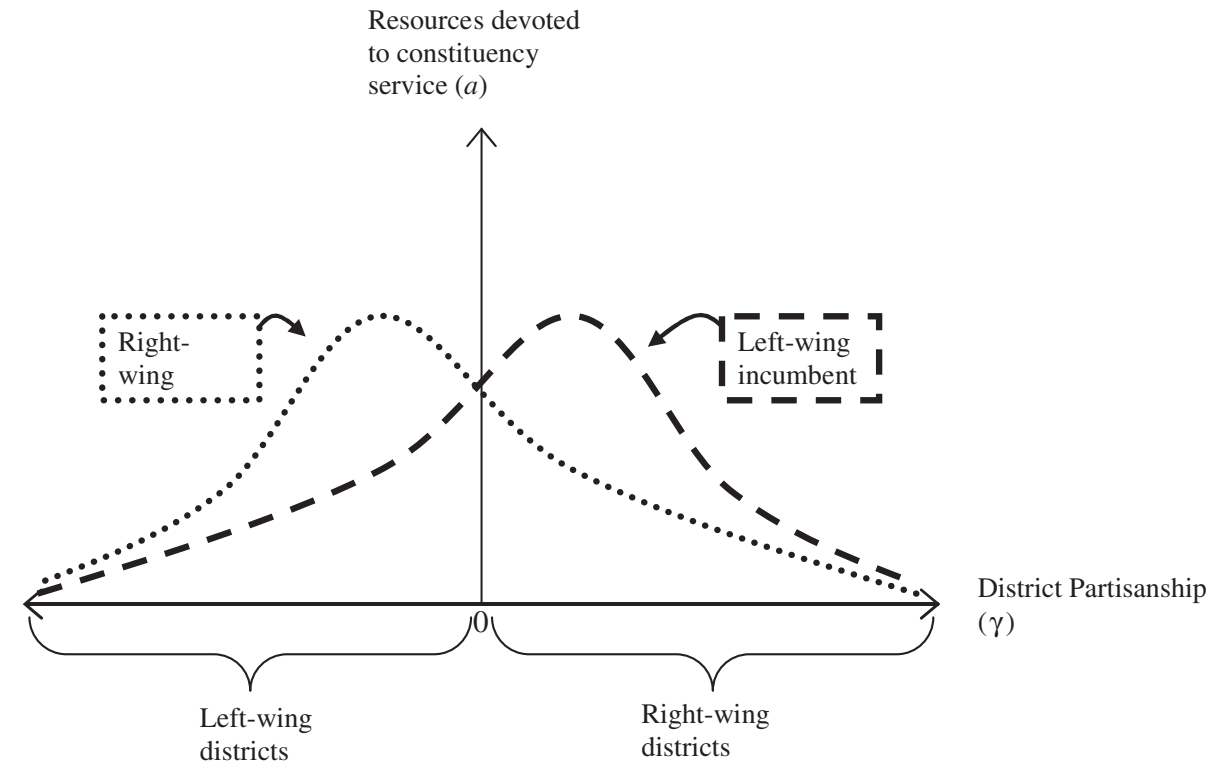

Increasing constituency service in a district with partisan leanings has two effects. First, as described in Remark 1, it increases the voter's belief about the incumbent's ability, on average. Second, increasing the provision of constituency service increases the amount of information the voter learns about the incumbent's ability. Intuitively, this is because the incumbent's success or failure at providing constituency service is more revealing of her ability the greater is the share of her resources devoted to constituency service.

The more balanced a district is between the two parties, the more powerful is the first effect. This is because, the more evenly divided the district, the larger the role the voter's belief about the incumbent's ability plays in the voter's reelection decision. Thus, the first effect tends to make constituency service provision highest in evenly balanced districts.

Greater information revelation is in the interest of an incumbent in a district where the voters lean against her party. This is because, in a district that is inclined to vote against the incumbent for policy reasons, she is willing to take bigger risks (that is, reveal more information about herself) to prove that she is of high ability. If the district leans in the direction of the candidate, alternatively, she has an incentive to play it safe and not reveal too much information. The second effect, then, tends to make left-wing (right-wing) incumbents provide more con- stituency service in more right-wing (left-wing) districts. The interplay of the two effects gives rise to the proposition and is illustrated in Figure 2.

Of course, left-wing districts are more likely to have left-wing incumbents and right-wing districts are more likely to have right-wing incumbents. Assuming that the probability there is a left-wing incumbent in a given district that leans left is equal to the probability there is a right-wing incumbent in another district that leans equally right, the following result follows from the previous proposition.

Corollary 1 On average, constituency service is increasing in district-level partisan balance.

While many other intervening factors would have to be controlled for to make a strong causal claim, Corollary 1 is consistent, broadly speaking, with historical evidence from the United States. In particular, starting in the mid-1960s, Congressional incumbents began devoting more time and resources to constituency service (see Shepsle (1989) and Figure 1). This occurred concomitant with a decrease in the strong partisan leanings of many districts.

For much of the twentieth century, most Congressional districts leaned strongly toward one or the other party. The south was solidly Democratic, while the nonurban parts of the north and west were solidly Republican. This pattern changed in the 1960s, due in part to the debate over civil rights. In addition, Cox 
and Katz (2002) show that redistricting in the wake of Baker v. Carr (decided in 1962) led to the end of many safe Republican districts in the north. As a result, district level electorates became more balanced on average, in the sense that the median voter of a district was more likely to be close to indifferent between the two parties. This manifested itself most clearly in the fact that southern states, which had previously only elected Democrats, began sometimes to vote Republican in Congressional and statewide elections. This trend has been noted by a variety of scholars. Erikson, Wright, and McIver (1993) report that public opinion in the early 1990s was roughly balanced between the two parties in most states, which was certainly not true in 1960. Moreover, Ansolabehere and Snyder (2002) find that the portion of vote shares explained by the states' partisan leanings ("the normal vote") has declined dramatically since mid-century. They write:

The normal vote accounts for 53 percent of the variation in the vote in the 1940s. Its importance drops substantially in the 1950s, to 40 percent of total variance in the vote. And it collapses in the 1960s, explaining only 20 percent of the variance in the vote in the 1960s and 1970s ... falling to 10 percent in the 1980 s and 1990 s.

Consistent with Corollary 1, partisan balance and constituency service increased together.

While the above discussion increases our confidence in our model, it is far from conclusive. A variety of confounding factors have not been considered. For example, careful observers of American politics will note that, while state level partisan balance has increased since the 1960s, some individual districts have become less balanced because gerrymandering has created "safe" seats, especially in the past decade. For example, the number of House seats that are won in a landslide (that is, with over $60 \%$ of the vote) has trended upward (Ornstein, Mann, and Malbin 2002). This, of course, does not disconfirm our hypothesis. Landslide elections do not measure the notion of partisan balance to which we are appealing, which is how close the median voter in a district is to indifferent between the two parties' ideologies. This is because measures of party vote share include a variety of factors besides ideology. Perhaps most importantly, vote share incorporates the incumbency advantage, which has also been trending upward (Ansolabehere and Snyder 2002). To fully test our over time prediction, one needs a measure of district-level partisan leanings that is independent of actual electoral outcomes. We discuss some potential empirical strategies in the conclusion.

\section{Executive Independence}

Institutional differences can alter incentives for providing constituency service by changing the weight voters place on policy versus ability concerns. In order to explore this possibility, we compare stylized models of systems with a separately elected executive (the presidential system) and without a separately elected executive (the parliamentary system). In order to focus on the institutional variation, we return to the simpler model where all district ideal points have mean 0 .

There are, of course, a variety of factors that differentiate parliamentary from presidential systems: cabinet formation, votes of confidence, etc. Moreover, many of these affect constituency service in one way or another. Thus, we do not want to make strong claims that our highly stylized model captures all, or even most, of the factors that may cause variance in constituency service between presidential and parliamentary systems. Rather, in order to explore how institutional variation matters, we focus on one important difference between these two types of systems - executive independence.

In the parliamentary system policy is fully determined by the legislature (it is the average of legislative ideal points, denoted $x_{\mathrm{L}}$ ). In a presidential system, the legislature must bargain with the president to determine national policy. Following Alesina and Rosenthal (1995), we assume that policy in a presidential system is a weighted average of the legislature's proposal and the president's ideal point, with weight $\beta$ on the legislative proposal: $x=\beta x_{\mathrm{L}}+(1-\beta) x_{\mathrm{P}}$. We also assume that $x_{\mathrm{P}}$ is a mean zero, normal random variable. This implies that the president is equally likely to be from either party.

Just as before, the voter chooses which candidate to select by comparing the expected utility of each choice. Lemma 1 shows that, in the parliamentary system, the voter elects the left-wing candidate if and only if

$$
m_{L} \geq \eta^{\text {Parl }}+m_{R}
$$

where $\eta^{\text {Parl }}$ is, again, the policy component of the voter's decision (formally defined in the appendix). The voter's election rule in a presidential system is similar. However, the diminished effect of the legislature on national policy affects the voter's calculus. Intuitively, because the legislature only partially controls national policy, the voter worries somewhat less about policy in casting his legislative vote. This frees the voter to put more weight on ability considerations and, thus, constituency service. 
Lemma 4 In the presidential system, the voter votes for the left-wing candidate if and only if $m_{L} \geq \beta \eta^{\text {Parl }}$ $+m_{R}$.

Just as in the parliamentary case, the voter's decision about whether or not to reelect an incumbent takes into account two factors: the voter's beliefs about the relative abilities of the two candidates and the voter's partisan preferences.

Now we can see exactly how the existence of an independent executive influences the level of resources devoted to constituency service. The $\beta$ term in the policy component of the voter's decision rule in the presidential system reflects the fact that voters put relatively less weight on policy concerns in their choice of legislators in the presidential system. This is because the voters know that the president also has an impact on policy. As such, the voters pay more attention to the ability of legislative candidates in the presidential system and, consequently, constituency service has a greater expected impact on reelection, increasing incentives for the incumbent to provide constituency service.

Proposition 3 Constituency service provision is greater in the presidential system than in the parliamentary system.

This result is broadly consistent with comparative empirical evidence. For instance, legislators in United States' presidential system exert significantly more effort toward providing constituency service than do legislators in the United Kingdom's parliamentary system (Cain, Ferejohn, and Fiorina 1987).

The comparison between the parliamentary and presidential systems also gives rise to a further result with applicability to comparative legislativeelectoral politics. The presidential system leads to greater provision of constituency service because the president's role in determining national policy causes voters to focus more on local concerns when choosing their legislator. Intuitively, then, within a presidential system, the more powerful the president is relative to the legislature (smaller $\beta$ ), the more the voters will focus on constituency service in legislative elections and so the more constituency service will be provided.

Corollary 2 All else equal, within a presidential system, the stronger the president is relative to the legislature the greater the level of constituency service.

\section{Single-Member versus Multimember Districts}

We now consider the comparison between a stylized single-member district (SMD) system and a stylized multimember district (MMD) system in which the voter is represented by two legislators and can cast a vote for each seat (that is, the incumbents are not running against one another). Of course, because most legislatures are multicameral, in general voters have multiple representatives, often from overlapping districts. Our model is meant to capture the marginal impact of adding an additional representative. This stylization reflects only one of the large variety of types of multimember district systems. Later we show how the intuitions developed here can be adapted to lend insight into other types of multimember district system-focusing on Japan prior to the electoral reform.

In order to explore this idea, we specialize our interpretation of $a$ to resources devoted to procuring pork. Unlike constituency service, which is provided to a specific voter by a specific incumbent, the voter cannot precisely apportion credit for pork-barrel projects.

The voters observe the total amount of pork provided to the district, but not the amount produced by individual legislators. This creates free-riding by representatives in the MMD system that does not exist in the SMD system. The voter uses the information he gains by observing pork provision to update his beliefs regarding his representatives' ability levels and, consequently, expected future pork provision. The voter's updated beliefs regarding candidate ability dictate his reelection decisions. This creates incentives for politicians to provide pork. However, in the MMD system each representative receives credit for only a share of the local goods she provides to her district, and she receives some credit for local goods provided by the other member of her delegation as well, creating an incentive to free-ride. In the SMD system this problem does not exist, since all local goods are credited to the sole representative. Thus, the model predicts that legislators in the MMD system invest fewer resources in legislative particularism than legislators in the SMD system.

Proposition 4 All else equal, incumbent legislators from the MMD system will devote fewer resources to local public goods provision than legislators from the SMD system.

While the model is clearly stylized, the result in Proposition 4 is consistent with the empirical obser- 
vations of Heitshusen, Young, and Woods (2005), Welch and Studlar (1990), and Jewell (1982), who find that MMD legislators do less constituency-related work than SMD legislators. In our model, this is because, within a multimember delegation, incentives to free-ride lead to under-provision of local public goods. Of course, the relationship between the model and the empirical studies is not exact. Even voters choosing representatives for single-member district legislative houses face some degree of information pooling, since the upper house also plays a role in determining legislative outputs. Nonetheless, the comparative static holds-adding an additional representative to a district's delegation increases information pooling and, therefore, decreases local goods provision.

\section{Divided Delegations and Bailiwicks}

We have argued that multimember districts create information pooling which reduces the total supply of local goods. This is bad for the voter when his relative prioritization of local versus global public goods is such that the legislator is under-providing local goods from the voter's point of view. (Lemma 3 demonstrates that this is true when $\alpha<\bar{\alpha}$.) In this section, we consider some possible responses to the free-rider problem posed by the MMD system: divided delegations and bailiwicks.

\section{Divided Delegations}

Voters in a multimember district have an incentive to elect representatives from two different parties, since this may "solve" the free-rider problem for their representatives. A slight variation of the MMD model makes it possible to identify conditions under which voters will choose to elect a divided delegation.

Unlike constituency service, voters and politicians of different partisan orientations may have preferences for different types of pork. For instance, in the United States, Republicans are more likely to procure pork reflecting industry interests while Democrats are more likely to procure pork that benefits public sector unions.

Assume that there are two different types of pork: conservative and liberal. Legislators from party $R$ produce conservative pork while those from party $L$ produce liberal pork. Let $y_{t}^{C}$ be the amount of conservative pork provided in round $t$, and let $y_{t}^{L}$ be the amount of liberal pork provided in round $t$. The voter's round $t$ utility from pork is

$$
u_{t}\left(y_{t}^{C}, y_{t}^{L}\right)=\left(1-\psi\left(x^{*}\right)\right) y_{t}^{C}+\psi\left(x^{*}\right) y_{t}^{L},
$$

where $0<\psi\left(x^{\star}\right)<1$ for all $x^{\star}, \psi(\cdot)$ is strictly decreasing, and $\psi(0)=\frac{1}{2}$. Thus a voter's ideological preferences for pork are correlated with his preferences for national policy.

If the voter chooses a divided delegation, she can properly assess the contribution of each legislator (up to the stochastic element), just as in the SMD system, since the two different types of pork are distinguishable. Conservative pork constitutes a signal of the right-wing legislator's ability while liberal pork constitutes a signal of the left-wing legislator's ability. Thus, as an immediate consequence of Proposition 4, we have:

Proposition 5 Provision of local goods in the MMD system is greater in divided delegations than in unified delegations.

Consider a voter who must choose which candidate to elect before date 1. From Proposition 5, we know that a divided delegation will produce more local goods for the voter's district than will a unified delegation. However, a voter with partisan preferences (that is, $x^{*} \neq 0$ ) faces a trade-off. On the one hand, if he chooses a divided delegation he will benefit from more local goods provision. On the other hand, some of the local goods will be of the less desirable type and national policy will be pushed away from his ideal point.

This trade-off implies that only more extreme voters will select unified delegations. Such voters are willing to forgo extra local goods in exchange for securing both local and national policies that conform to their ideologies. Less partisan voters will be inclined to choose divided delegations in order to maximize the amount of local goods procured for the district. This basic logic leads to the following proposition.

Proposition 6 In MMDs, sufficiently moderate voters ( $x^{*}$ close enough to 0 ) will choose a divided delegation, while extreme voters will choose their preferred type of unified delegation.

The extension of the model is consistent with the standard, intuitive view that more moderate voters prefer divided delegations while more extremist voters prefer unified delegations of their own ideological persuasion (Fiorina 1996). However, the logic differs from the standard intuition that voters might want divided delegations in order to cause gridlock. Rather, this model suggests that voters choose a divided delegation in order to encourage the provision of more 
local goods for their constituency, trading this off against their ideological preferences. Moreover, this extension of the model suggests a novel and testable hypothesis: divided delegations will enjoy more pork than unified delegations.

\section{Bailiwicks}

Carey and Shugart (1995) note that in multimember district systems like that used in Japan prior to 1994, incumbents provided very high levels of local goods relative to other MMD systems. This fact seems to contradict our results. However, our model suggests an institutional explanation of the Japanese experience. MMD incumbents in our model provide low levels of constituency service because of the free-rider problem discussed above. In Japanese multimember districts this informational problem was mitigated by the institution of koenkai, or personal constituencies (Hirano 2002; Richardson 1988). These bailiwicks created the same informational effect as SMDs or divided delegations because each incumbent specialized in providing for his or her subconstituency. Local goods provision was high in Japan, then, in part because the ubiquity of personal constituencies changed the informational environment and thereby diminished the incentive to free-ride. Thus, the model highlights an important institutional subtlety for understanding comparative legislatures. What matters is not precisely whether the legislature has multi- or single-member districts, but rather the amount of information revealed as the result of institutional and strategic considerations.

\section{Conclusion}

We have analyzed a model of legislative particularism in a variety of stylized institutional and electoral environments. While the model omits a host of important determinants of constituency service, the comparative statics of the model seem to be consistent with both comparative evidence and over-time trends in the United States. Moreover, the over-time trends we address are not explained by existing models that focus on parties as the determinant of constituency service. A more complete model, of course, would integrate party discipline, informative party labels, and the electoral and institutional dynamics we explore.

The empirical literature seems broadly supportive of our model, providing some evidence that the causal mechanisms we identify are important complements to party strength in determining the level of constituency service. However, rigorous empirical testing is clearly needed to further evaluate the model. Three areas in which our model yields relatively novel implications seem amenable to future empirical work.

The model predicts districts with greater partisan balance will enjoy more constituency service. Several approaches could be employed to test this hypothesis directly. One could combine existing data on the use of Congressional resources with surveys assessing the preferences of the median voter in each Congressional district. Alternatively, one could measure legislative particularism in state legislatures and the use-voting patterns for low-visibility, statewide offices to assess the district-level normal vote.

The analysis also indicates that, within presidential systems, the greater the president's influence over national policy the more constituency service legislators will do. This hypothesis could be tested in two ways. Within a single country, electoral reforms that alter the institutional strength of the executive (such as occurred in Israel in 1992 (Bueno de Mesquita 2000)) could be used as natural experiment. Further, one could test the hypothesis comparatively by measuring legislative particularism in different presidential regimes as has been done, for example, in Latin America (Ames 2001; Crisp and Ingall 2002).

Finally, the model suggests that in a multimember district legislature, districts with divided delegations will benefit from more local goods than districts with unified delegations. This hypothesis could be evaluated by examining U.S. state legislatures with multimember district systems. Thus, while more work is needed, the model presented here is consistent with known empirical trends, addresses empirical facts not explained by other models, and yields novel hypotheses that are amenable to future empirical testing.

\section{Acknowledgments}

We are indebted to Jim Alt, Bruce Bueno de Mesquita, Charles Cohen, Dan Gingerich, Ken Kollman, Jonathan Nagler, Ken Shepsle, Steve Smith, Alan Wiseman, the participants in the Harvard Political Economy Workshop, and seminar audiences at Cornell, Northwestern, NYU, and Washington University for valuable comments. This paper builds on and subsumes Bueno de Mesquita's earlier paper entitled "Less than the Sum of Its Parts: Monitoring Legislative Teamwork in Multimember Districts."

Manuscript submitted 1 December 2004

Manuscript accepted for publication 3 June 2005 


\section{References}

Aldrich, John H. 1995. Why Parties?: The Origin and Transformation of Political Parties in America. Chicago: University of Chicago Press.

Alesina, Alberto, and Guido Tabellini. 2003. "Bureaucrats or Politicians?” NBER Working Paper no. 9809.

Alesina, Alberto, and Howard Rosenthal. 1995. Partisan Politics, Divided Government, and the Economy. New York: Cambridge University Press.

Ames, Barry. 2001. The Deadlock of Democracy in Brazil. Ann Arbor: University of Michigan Press.

Ansolabehere, Stephen, and James M. Snyder, Jr. 2002. “The Incumbency Advantage in U.S. Elections: An Analysis of Stage and Federal Offices, 1942-2000." Election Law Journal 1 (September): 315-38.

Ashworth, Scott. 2005. "Reputational Dynamics and Political Careers." Journal of Law, Economics and Organization. Forthcoming.

Ashworth, Scott, and Ethan Bueno de Mesquita. 2004. "Party Discipline with Institutional and Electoral Variation." IGS Working Paper 2004-7.

Bueno de Mesquita, Ethan. 2000. "Strategic and Non-Policy Voting: A Coalitional Analysis of Israeli Electoral Reform." Comparative Politics 33 (October): 63-80.

Cain, Bruce, John Ferejohn, and Morris Fiorina. 1987. The Personal Vote: Constituency Service and Electoral Independence. Cambridge: Harvard University Press.

Carey, John M., and Matthew Shugart. 1995. "Incentives to Cultivate a Personal Vote: A Rank Ordering of Electoral Formulas." Electoral Studies 14 (December): 417-39.

Cox, Gary W., and Jonathan N. Katz. 2002. Elbridge Gerry's Salamander: The Electoral Consequences of the Reapportionment Revolution. New York: Cambridge University Press.

Cox, Gary W., and Matthew D. McCubbins. 1993. Legislative Leviathan: Party Government in the House. Berkeley: University of California Press.

Crisp, Brian F., and Rachael E. Ingall. 2002. "Institutional Engineering and the Nature of Representation: Mapping the Effects of Electoral Reform in Colombia." American Journal of Political Science 46 (October): 733-48.

Dewatripont, Mathias, Ian Jewitt, and Jean Tirole. 1999. “The Economics of Career Concerns, Part II: Application to Missions and Accountability of Government Agencies." Review of Economic Studies 66 (January): 199-217.
Erikson, Robert S., Gerald C. Wright, and John P. McIver. 1993. Statehouse Democracy: Public Opinion and Policy in the American States. Cambridge: Cambridge University Press.

Fiorina, Morris P. 1996. Divided Government. Boston: Allyn and Bacon.

Fiorina, Morris P., and Douglas Rivers. 1989. "Constituency Service, Reputation, and the Incumbency Advantage." In Home Style and Washington Work, eds. Morris P. Fiorina and David Rohde. Ann Arbor: University of Michigan Press, pp. 17-45.

Heitshusen, Valerie, Garry Young, and David M. Woods. 2005. "Electoral Context and MP Constituency Focus in Australia, Canada, Ireland, New Zealand, and the United Kingdom." American Journal of Political Science 49 (January): 32-45.

Hirano, Shigeo. 2002. "Estimating the Personal Vote in Japanese Politics.” Unpublished paper, Harvard University.

Holmström, Bengt. 1999. "Managerial Incentive Problems: A Dynamic Perspective." Review of Economic Studies 66 (January): 169-82.

Jewell, Malcolm. 1982. Representation in State Legislatures. Lexington: University Press of Kentucky.

Lohmann, Susanne. 1998. "An Informational Rationale for the Power of Special Interests." American Political Science Review 92 (December): 809-27.

Ornstein, Norman J., Thomas E. Mann, and Michael J. Malbin. 2002. Vital Statistics on Congress, 2001-2002. Washington: American Enterprise Institute for Public Policy Research.

Persson, Torsten, and Guido Tabellini. 2000. Political Economics: Explaining Economic Policy. Cambridge: MIT Press.

Richardson, Bradley M. 1988. "Constituency Candidates Versus Parties in Japanese Voting Behavior." American Political Science Review 82 (September): 695-718.

Rohde, David W. 1991. Parties and Leaders in the Postreform House. Chicago: University of Chicago Press.

Sandler, Todd. 2004. Global Collective Action. Cambridge: Cambridge University Press.

Shepsle, Kenneth A. 1989. "The Changing Textbook Congress." In Can the Government Govern?, eds. John Chubb and Paul Peterson. Washington: Brookings Institution.

Welch, Susan, and Donley T. Studlar. 1990. "Multi-Member Districts and the Representation of Women: Evidence From Britain and the United States." Journal of Politics 52 (May): 391-412.

Scott Ashworth is assistant professor of politics, Princeton University, Princeton, NJ 08544. Ethan Bueno de Mesquita is assistant professor of political science, Washington University, St. Louis, MO 63130. 


\title{
Appendix to "Delivering the Goods: Legislative Particularism in Different Electoral and Institutional Settings"
}

\author{
Scott Ashworth* and Ethan Bueno de Mesquita ${ }^{\dagger}$
}

\section{Proof of Lemma 1}

Let $a^{F B}=\arg \max _{a} \theta(a+u(D-a))$, and let $V=a^{F B}+\alpha u\left(D-a^{F B}\right)$. At the final date, it is obvious that any legislator will choose $a^{F B}$. The voter's total second period payoff is $\mathbb{E}\left(-\left(x^{*}-\tilde{x}_{W}\right)^{2}+\theta_{W} V+\epsilon\right)$, where $W$ is the winner of the election and $\tilde{x}_{W}$ is the random variable representing national policy when $W$ wins the election in the voter's district.

Without loss of generality, we will focus on the case where the incumbent is from party $L$. A voter votes for $L$ if and only if

$$
\mathbb{E}\left(-\left(\tilde{x}_{L}-x^{*}\right)^{2}+\theta_{L} V+\epsilon\right) \geq \mathbb{E}\left(-\left(\tilde{x}_{R}-x^{*}\right)^{2}+\theta_{R} V+\epsilon\right)
$$

where $m_{L}\left(m_{R}\right)$ is the voter's expectation about the ability of candidate $L(R)$. Take expectations and rearrange terms to see that this is true if

$$
-\mathbb{E}\left(\tilde{x}_{L}-x^{*}\right)^{2}+m_{L} V \geq-\mathbb{E}\left(\tilde{x}_{R}-x^{*}\right)^{2}+m_{R} V .
$$

Thus the reelection condition reduces to $x^{*} \leq \frac{\left(m_{L}-m_{R}\right) V}{2\left(\mu_{R}-\mu_{L}\right)}$.

For a given $g$, let $m_{L}(g)$ be the posterior belief given the signal $g$. the incumbent is reelected if and only if $x^{*} \leq \frac{\left(m_{L}(g)-m_{R}\right) V}{2\left(\mu_{R}-\mu_{L}\right)}$, or

$$
m_{L}(g) \geq \frac{2\left(\mu_{R}-\mu_{L}\right) x^{*}}{V}+m_{R}
$$

Define $\eta=\frac{2\left(\mu_{R}-\mu_{L}\right) x^{*}}{V}$. Then $\eta$ is distributed $\mathcal{N}\left(0, \sigma_{\eta}^{2}\right)$, where $\sigma_{\eta}^{2}=\frac{4\left(\mu_{R}-\mu_{L}\right)^{2} \sigma_{x^{*}}^{2}}{V^{2}}$.

*Department of Politics, Princeton University.

${ }^{\dagger}$ Department of Political Science, Washington University. 


\section{Proof of Lemma 2}

Taking an affine transformation of equation (1) we find that the incumbent chooses

$$
a^{*}=\arg \max _{a} \mathbb{E}(\operatorname{Pr}(\text { reelect } \mid a, \theta) B+\theta(a+u(D-a))) .
$$

To fully specify the probability we combine the voting rule from Lemma 1 and the voter's updating rule which we derive now. If the voter assumes that the constituency service allocation is $a^{*}$, then he believes $g / a^{*} \sim \mathcal{N}\left(\theta, \sigma_{\theta}^{2}+\sigma_{\epsilon}^{2} /\left(a^{*}\right)^{2}\right)$, so standard results (DeGroot, 1970) imply that the posterior mean is $m^{\prime}=\lambda\left(a^{*}\right) \frac{g}{a^{*}}+\left(1-\lambda\left(a^{*}\right)\right) m$, where $\lambda\left(a^{*}\right)=\frac{\sigma_{\theta}^{2}}{\sigma_{\theta}^{2}+\sigma_{\epsilon}^{2} /\left(a^{*}\right)^{2}}$.

Thus, the incumbent is reelected if and only if $\lambda\left(a^{*}\right)\left(\frac{g}{a^{*}}-m\right)>\eta$ or

$$
\frac{g}{a^{*}}-m-\frac{\eta}{\lambda\left(a^{*}\right)}>0
$$

The left-hand side is distributed normally with mean $\frac{m a}{a^{*}}-m$ and standard deviation

$$
\sigma\left(a, a^{*}\right)=\sqrt{\left(\frac{a}{a^{*}}\right)^{2} \sigma_{\theta}^{2}+\frac{1}{a^{*}} \sigma_{\epsilon}^{2}+\frac{1}{\lambda\left(a^{*}\right)^{2}} \sigma_{\eta}^{2}}
$$

To simplify notation, define the opportunity cost of $a$ as $c(a)=\left(a^{F B}+u\left(D-a^{F B}-a-\right.\right.$ $u(D-a)) m$. Thus the incumbent solves

$$
\max _{a} B\left(1-\Phi\left(\frac{-\left(\frac{a}{a^{*}}-1\right) m}{\sigma\left(a, a^{*}\right)}\right)\right)-m c(a) .
$$

The first-order condition is

$$
-B \phi\left(\frac{-\left(\frac{a}{a^{*}}-1\right) m}{\sigma\left(a, a^{*}\right)}\right) \frac{-m / a^{*} \sigma-\left((m a) / a^{*}-m\right) \sigma_{a}}{\sigma^{2}}=m c^{\prime}(a) .
$$

Imposing rational expectations $\left(a=a^{*}\right)$ implies the equilibrium condition

$$
\frac{B \phi(0)}{a^{*} \sigma\left(a^{*}, a^{*}\right)}=c^{\prime}\left(a^{*}\right)
$$

Next, we prove that the equation has a unique solution. Notice that

$$
a \sigma(a, a)=a \sqrt{\sigma_{\theta}^{2}+\frac{1}{a} \sigma_{\epsilon}^{2}+\frac{\sigma_{\theta}^{2}+\sigma_{\epsilon}^{2} / a^{2}}{\sigma_{\theta}^{2}} \sigma_{\eta}^{2}}=\sqrt{a^{2} \sigma_{\theta}^{2}+\sigma_{\epsilon}^{2}+\left(a^{2}+\frac{\sigma_{\epsilon}^{2}}{\sigma_{\theta}^{2}}\right) \sigma_{\eta}^{2}}
$$


so $a^{*} \sigma\left(a^{*}, a^{*}\right)$ is increasing in $a^{*}$. Thus the left-hand side of the equilibrium condition is decreasing, and the right-hand side is increasing, so there is a unique solution.

The only other possibility for an equilibrium would be a corner solution at $a=0$. However, this is impossible. If the voter expects zero effort, then he does not update his beliefs about the incumbent's ability, and uses a reelection rule that is independent of the signal. Since the signal does not affect her reelection chances, she will choose her first-best effort allocation, which has $a>0$. Since equilibrium requires that the voter's expected action and the actual action be identical, this is not an equilibrium.

\section{Proof of Lemma 3}

The voter's preferred level of constituency service is $a^{\prime}=\arg \max _{a} \theta a+\theta \alpha u(D-a)$. The first-order condition implies $1=\alpha u^{\prime}\left(D-a^{\prime}\right)$. It is clear from this first-order condition that $\lim _{\alpha \rightarrow 0} a^{\prime}=D$. Since $a^{*}<D$ in the limit there is under provision. By continuity, there is some positive $\bar{\alpha}$ such that there is under provision for $\alpha<\bar{\alpha}$.

\section{Proof of Proposition 1}

The incumbent solves

$$
\max _{a} \operatorname{Pr}\left(\text { reelect } \mid a, a^{*}, m\right) B+\theta(a+u(D-a))
$$

Since $u$ is concave, $u(D-a)$ has increasing differences. Thus, the objective function is supermodular and Topkis' Theorem implies that $a^{*}$ is increasing in $D$ (Topkis, 1978).

\section{Proof of Proposition 2}

As before, the incumbent is reelected if $\frac{g}{a^{*}}-m-\frac{\eta}{\lambda\left(a^{*}\right)}>0$. Now the left-hand side is distributed normally with mean $\frac{m a}{a^{*}}-m-\hat{\gamma}$ and standard deviation $\sigma\left(a, a^{*}\right)=\sqrt{\left(\frac{a}{a^{*}}\right)^{2} \sigma_{\theta}^{2}+\frac{1}{a^{*}} \sigma_{\epsilon}^{2}+\frac{1}{\lambda\left(a^{*}\right)^{2}} \sigma_{\eta}^{2}}$, 
where $\hat{\gamma}=\frac{1}{2 \lambda\left(a^{*}\right)}\left(\mu_{R}-\mu_{L}\right) \gamma$. Thus the incumbent solves

$$
\max _{a} B\left(1-\Phi\left(\frac{-\left(\frac{a}{a^{*}}-1\right) m+\hat{\gamma}}{\sigma\left(a, a^{*}\right)}\right)\right)-m c(a)
$$

The first-order condition is

$$
-B \phi\left(\frac{-\left(\frac{a}{a^{*}}-1\right) m+\hat{\gamma}}{\sigma\left(a, a^{*}\right)}\right) \frac{-m / a^{*} \sigma+\left((m a) / a^{*}-m-\hat{\gamma}\right) \sigma_{a}}{\sigma^{2}}=m c^{\prime}(a) .
$$

Imposing rational expectations $\left(a=a^{*}\right)$ implies the equilibrium condition

$$
\frac{B \phi\left(\frac{\hat{\gamma}}{\sigma\left(a^{*}, a^{*}\right)}\right)\left(m+a^{*} \hat{\gamma} \sigma_{a}\right)}{a^{*} \sigma\left(a^{*}, a^{*}\right)}=m c^{\prime}\left(a^{*}\right) .
$$

Since $\sigma\left(a, a^{*}\right)=\sqrt{\left(\frac{a}{a^{*}}\right)^{2} \sigma_{\theta}^{2}+\frac{1}{a^{*}} \sigma_{\epsilon}^{2}+\frac{1}{\lambda\left(a^{*}\right)^{2}} \sigma_{\eta}^{2}}$, we have $\sigma_{a}\left(a, a^{*}\right)=\frac{\frac{a}{a^{*}} \sigma_{\theta}^{2}}{\sigma\left(a, a^{*}\right)}$. Thus the equilibrium condition can be rewritten as

$$
B \phi\left(\frac{\hat{\gamma}}{\sigma\left(a^{*}, a^{*}\right)}\right) \frac{m+\frac{a^{*} \hat{\gamma}}{\sigma\left(a^{*}, a^{*}\right)}}{a^{*} \sigma\left(a^{*}, a^{*}\right)}=m c^{\prime}\left(a^{*}\right) .
$$

This equilibrium condition might have multiple solutions. We will say that a solution is stable if the left-hand side crosses the right-hand side from above. When this happens, small perturbations below the solution make the marginal benefit greater than the marginal cost, so the action will increase, and vice versa for perturbations above the solution. A standard application of the implicit function theorem shows that around a stable equilibrium the sign of $\frac{d a^{*}}{d \gamma}$ is the same as the sign of:

$$
\frac{\partial}{\partial \gamma} B \phi\left(\frac{\hat{\gamma}}{\sigma\left(a^{*}, a^{*}\right)}\right) \frac{m+\frac{a^{*} \hat{\gamma}}{\sigma\left(a^{*}, a^{*}\right)}}{a^{*} \sigma\left(a^{*}, a^{*}\right)}-m c^{\prime}\left(a^{*}\right) .
$$

Now for the comparative statics. $\phi(\gamma)$ is increasing on $\mathbb{R}_{-}$and decreasing on $\mathbb{R}_{+}$, while $\frac{m+a \gamma / \sigma}{a \sigma}$ is increasing everywhere. Since $\phi$ is maximized at 0 , the linear term dominates near $\gamma=0$. On the other hand, the normal density tends to zero faster than any polynomial, so the $\phi$ term dominates for large $\gamma$. Thus for a $L$ incumbent, effort is increasing as $\gamma$ increases up to some $\gamma^{*}>0$, and then decreases. Thus constituency service is maximal for an incumbent whose district leans somewhat against her party. 


\section{Proof of Lemma 4}

As before, let $\tilde{x}_{L}\left(\tilde{x}_{R}\right)$ be the legislature's policy stance if the voter elects $L(R)$. Now overall policy is $\beta \tilde{x}_{L}+(1-\beta) x_{P}\left(\beta \tilde{x}_{R}+(1-\beta) x_{P}\right)$. The voter votes for $L$ if and only if

$$
\mathbb{E}\left(-\left(\beta \tilde{x}_{L}+(1-\beta) x_{P}-x^{*}\right)^{2}+\theta_{L} V\right) \geq \mathbb{E}\left(-\left(\beta x_{R}+(1-\beta) x_{P}-x^{*}\right)^{2}+\theta_{R} V\right)
$$

Algebra just like that in the proof of Lemma 1 shows that this condition is equivalent to

$$
m_{L} \geq \frac{2 \beta\left(\mu_{R}-\mu_{L}\right) x^{*}}{V}+m_{R}
$$

\section{Proof of Proposition 3}

In the presidential system, the incumbent is reelected given a level of constituency service $(g)$ if and only if $x^{*} \leq \frac{\left(m_{L}(s)-m_{R}\right) V}{(2 \beta / n)\left(\mu_{R}-\mu_{L}\right)}$, or

$$
m_{L}^{\prime}(g) V \geq(2 \beta / n)\left(\mu_{R}-\mu_{L}\right) x^{*}+m_{R} V
$$

We define $\eta^{\text {pres }}=\frac{2 \beta\left(\mu_{R}-\mu_{L}\right) x^{*}}{n V}$. Then $\eta^{\text {pres }}$ is normally distributed with mean 0 and variance $\sigma_{\eta^{p r e s}}^{2}=\frac{4 \beta^{2}\left(\mu_{R}-\mu_{L}\right)^{2} \sigma_{x^{*}}^{2}}{n^{2} V^{2}}$. Thus $\sigma_{\eta}^{2}$ is increasing in $\beta$, so $\sigma(a, a)$ is increasing in $\beta$, and Theorem 1 from Milgrom and Roberts (1994) implies that $a^{*}$ is decreasing in $\beta$.

\section{Proof of Proposition 4}

In an MMD, the voter's signal is $g=\theta_{1} a_{1}+\theta_{2} a_{2}+\epsilon$. Let the voter expect efforts $a_{1}^{*}$ and $a_{2}^{*}$. Then $\frac{g-m a_{2}^{*}}{a_{1}^{*}}$ is normally distributed with mean $\theta$ and variance $\frac{\sigma_{\theta}^{2} a_{1}^{2}+\sigma_{\theta}^{2}\left(a_{2}^{*}\right)^{2}+\sigma_{\epsilon}^{2}}{\left(a_{1}^{*}\right)^{2}}$. This is just like the SMD case, except the noise variance is greater by $\frac{a_{2}^{2}}{a_{1}^{2}} \sigma_{\theta}^{2}$. Thus a symmetric equilibrium of the MMD case satisfies the same equation as the SMD case with $\sigma$ uniformly greater. Thus Theorem 1 from Milgrom and Roberts (1994) implies that the equilibrium effort is less. 


\section{Proof of Proposition 6}

First, notice that a voter with $x^{*}=0$ has a strictly dominant strategy to elect a divided

delegation. Furthermore, if $x^{*}>0$ then both $R$ strictly dominates both $L$ and if $x^{*}<0$ then both $L$ strictly dominates both $R$. We will show that there is a critical value $\bar{x}$ such that both $R$ is optimal if $x>\bar{x}$ and a divided delegation is optimal for $\bar{x}>x>0$. A similar argument applies to voters with $x^{*}<0$.

The incremental return from switching from both $R$ to a divided delegation is

$$
\begin{array}{r}
\Delta\left(x^{*}\right)=-\left(x^{*}-\mu_{L}\right)^{2}+\left(x^{*}-\mu_{R}\right)^{2}+\theta\left(a_{S M D}^{*}-2 a_{M M D}^{*}\right)+2 \theta \psi\left(x^{*}\right) a_{M M D}^{*}+ \\
2 \alpha\left(u\left(D-a_{S M D}^{*}-u\left(D-a_{M M D}^{*}\right)\right),\right.
\end{array}
$$

which can be rewritten

$$
\begin{aligned}
2 x^{*}\left(\mu_{L}-\mu_{R}\right)+\left(\mu_{R}^{2}-\mu_{L}^{2}\right)+\theta\left(a_{S M D}^{*}-2 a_{M M D}^{*}\right)+ & 2 \theta \psi\left(x^{*}\right) a_{M M D}^{*}+ \\
& 2 \alpha\left(u\left(D-a_{S M D}^{*}-u\left(D-a_{M M D}^{*}\right)\right) .\right.
\end{aligned}
$$

This is decreasing in $x^{*}$ since $\left(\mu_{L}-\mu_{R}\right)<0$ and $\psi$ is decreasing. Thus if both $R$ is optimal for $x^{*}\left(\Delta\left(x^{*}\right) \geq 0\right)$, then both $R$ is the unique optimum for all $x$ greater than $x^{*}$. Furthermore, $\Delta\left(x^{*}\right)$ decreases without bound as $x^{*} \rightarrow \infty$, so the inequality holds for some $x^{*}$ great enough.

\section{References}

DeGroot, Morris H. 1970. Optimal Statistical Decisions. New York: McGraw-Hill.

Milgrom, Paul and John Roberts. 1994. "Comparing Equilibria." American Economic Review 84 (June): 441-459.

Topkis, Donald. 1978. "Minimizing a Submodular Function on a Lattice." Operations Research 26 (March): 305-321. 